Del sacar de otras pinturas. Consideración de las copias pictóricas a la luz de los tratados y otros textos del Renacimiento: reputación teórica versus repercusión práctica

Miquel Àngel Herrero-Cortell

Universitat de Lleida (España) 



\title{
Del sacar de otras pinturas. Consideración de las copias pictóricas a la luz de los tratados y otros textos del Renaci- miento: reputación teórica versus repercusión práctica
}

\section{Consideration of pictorial copies in the light of the treatises and other texts of the Renaissance: theoretical reputation ver- sus practical repercussion}

\author{
Miquel Àngel Herrero-Cortell \\ Universitat de Lleida (España) \\ miquelangel.herrero@hahs.udl.cat
}

Fecha de recepción: 07/05/2017

Fecha de aceptación: 18/12/2017

\begin{abstract}
Resumen
Las copias pictóricas durante el Renacimiento gozaron de un auge inusitado hasta entonces. Este apogeo se debió a los diversos fines para los que sirvieron: como parte de los procesos didácticos y de aprendizaje del oficio de la pintura; como sistema instrumental para la fijación y difusión de modelos; como mecanismo expeditivo en los talleres; y como forma de seriación o repetición de modelos afortunados, a veces incurriendo en el plagio o la falsificación. El presente artículo establece una confrontación entre la reputación teórica de las copias pictóricas aparentemente despreciadas u obviadas en la literatura artística-, y su verdadera repercusión práctica, que supuso que se crearan diversas maneras de entenderlas, y juzgarlas, en función de sus fines. Con ello se pretende enfrentar dos realidades paralelas: la del ámbito ideológico-teórico versus la realidad práctica.

Palabras clave: Copias; Pintura; Tratadística; Práctica artística; Renacimiento

Abstract

Pictorial copies during the Renaissance enjoyed an unprecedented boom until then. This peak arose due to the impulse of the various purposes for which those copies served: as part of the learning processes of the craft of painting; as an instrumental system for fixing and disseminating models; as expeditious mechanism for workshops; and as a form of serialization or repetition of fortunate models, sometimes even committing plagiarism or forgery. This paper focuses on a confrontation between theoretical reputation -copies were apparently neglected or
\end{abstract}




\section{Del sacar de otras pinturas. Consideración de las copias... - M.À. Herrero-Cortell}

obviated in the artistic and pictorial treatises-, and its real practical impact, which meant different approaches and ways to understand such practice, depending on their final purposes. This way two parallel realities can be faced: the ideological and theoretical level versus the actual practice.

Keywords: Copies; Painting; Treatises; Artistic practice; Renaissance

Para citar este artículo: Herrero-Cortell, M. A. (2018). Del sacar de otras pinturas. Consideración de las copias pictóricas a la luz de los tratados y otros textos del Renacimiento: reputación teórica versus repercusión práctica. Revista de humanidades, n. 5, pp. 85-106. ISBN 1130-5029 (ISSN-e 2340-8995).

Sumario: 1. Introducción. De originales y copias; de conceptos y valores. 2. Usos y abusos de las copias pictóricas 3. Conclusiones. 4. Bibliografía

\section{INTRODUCGIÓN. DE ORIGINALES Y COPIAS; DE CONGEPTOS Y VALORES*}

El acto de la copia pictórica, entendida como un conjunto de procesos con propósitos bien distintos, fue un hecho común en los talleres de pintura tardomedievales y modernos. Se trataba de un ejercicio multifuncional, que hoy está perfectamente constatado, y que ha dado no pocos quebraderos de cabeza a los historiadores del arte, especialmente a aquellos ocupados en la disciplina formalista (Benhamou y Ginsburgh, 2006, pp. 253-283). Ya desde la baja Edad Media -pero especialmente en los inicios del Renacimiento-, diversos recetarios y libros técnicos para artistas recogen sistemas para simplificar las metodologías de captación y transposición del modelo ${ }^{1}$-hasta entonces básicamente ejecutadas a mano alzada- ${ }^{2}$, a través de la obtención de papeles transparentes, retículas, calcos de carbón, así como otros procedimientos mecánicos o semimecánicos ${ }^{3}$. Sin embargo, buena parte de la

$1{ }^{*}$ El presente trabajo se inscribe dentro de las actividades del grupo de investigación consolidado ACEM (Arte y Cultura de Época Moderna), financiado por la Generalitat de Catalunya, [2014SGR242] y cuenta también con el apoyo del Ministerio de Educación, Cultura y Deporte, mediante la concesión de una ayuda FPU [2014/01768] para el desarrollo de la tesis doctoral: "Procedimientos técnicos, soportes, y materiales empleados en los obradores pictóricos de la Corona de Aragón (S. XVXVI)".

Destacan por ejemplo el Liber Diversarum Arcium, de la Biblioteca de Montpellier, el Manuscrito de Pádua, el Libro del Arte de Cennino Cennini, la Tabula Vocabulis de Jan le Begue, el manuscrito titulado 'Reglas para pintar' de la Biblioteca de Santiago de Compostela, y otros textos, tanto del género de recetarios como del de tratados, además de otros escritos, que se irán desgranando en el presente artículo.

2 En centurias anteriores pudo llegar a importar la repetición del asunto y su solución compositiva, sin demasiadas concesiones a una mímesis formal. Es por ello que los procesos de copia 'a mano alzada' cumplían sobradamente con este propósito, y por tanto, la fidelidad y la exactitud con respecto a un determinado original no fueron, necesariamente, valores perseguidos en el acto de la copia.

3 Los diversos procedimientos técnicos utilizados para la realización de copias pictóricas constituyen un tema relativamente poco explorado, tanto en el ámbito de la Historia del Arte como en 
tratadística italiana e hispana (especialmente a partir de la segunda mitad del siglo XVI, y en centurias sucesivas), omite voluntariamente cualquier información acerca de procedimientos de copia, o bien deja entrever un posicionamiento abiertamente sancionador hacia este tipo de prácticas. Siendo entonces una actividad tan común y extendida en los territorios europeos cabe cuestionarse, paradójicamente, ¿por qué resulta tan escasa la consideración de la que gozaba esta industria servil, si se atiende a la literatura artística del momento? $\mathrm{O}$, ¿qué razones motivaron la fiscalización de una serie de prácticas que fueron de uso común entre los pintores, inclusive aquellos que, además de ejercer el oficio de la pintura eran también escritores? Y, por último, ¿a qué se debe tal ambigüedad?

El objetivo de este trabajo es comparar la reputación teórica de las copias -como se ha dicho, aparentemente despreciadas u omitidas en la literatura artística-, con su repercusión práctica. La presente investigación demostrará que surgieron diversas maneras de entenderlas en función de sus fines. Con ello se pretende enfrentar dos realidades: la del ámbito ideológico-teórico versus la realidad de la praxis. Ambas quedan referidas en las fuentes (especialmente la primera pero también la segunda), y pueden analizarse a partir de los textos, o bien desde de los abundantes ejemplos de pinturas de este periodo conservados, que constituyen una realidad alternativa, o al menos paralela, a la que parece arrojar la tratadística pictórica. En última instancia, esta praxis floreció en el mismo espacio y tiempo en el que la literatura la convertía en algo censurable contra lo que arremeter.

Cabría pues, empezar, afinando y matizando las diversas posturas que emergen en lo que puede considerarse el eterno 'debate de la copia', y rastreando cuándo comienza a percibirse un atisbo de crítica hacia esta praxis. Esta concepción peyorativa, relacionada con una cierta censura a la misma cuando no tiene un valor didáctico (Bambach, 1999, pp. 127-136), ya se entrevé en el texto de Ceninno Ceninni (ca.1390-1400), esgrimiendo en varias ocasiones la superior consideración del natural como referencia. A partir de entonces buena parte de los escritos dedicados a cuestiones pictóricas redundan en una actitud sobre el tema tan escurridiza como oscura, e incluso, en ocasiones, manifiestamente ambigua.

Pero antes de entrar en materia, resultará operativo clarificar algunos conceptos y valores ${ }^{4}$. En primer lugar, cabría presentar los términos inventio e imitatio ${ }^{5}$, muy frecuentes en la literatura coetánea y directamente relacionados con el concepto

el de la investigación técnica y procedimental de las Bellas Artes. Aún con ello, conviene mencionar algunos estudios relevantes como son el de Bambach (1999); el de Melli (2001, pp. 3-9): el de Gianferrari (2003, pp. 245-254); o el Galassi (2013, pp. 130-137).

4 Una buena aproximación terminológica puede encontrarse en Casini (2015: 299-318).

5 El término imitatio llegó a tener diversos significados en el Renacimiento. La imitatio podía entenderse como una imitación de los modelos clásicos; como mímesis platónica referida a la imitación de la Idea absoluta de la Belleza; como mímesis aristotélica fundamentada en la emulación de la naturaleza; o como copia desvirtuada (García, 1992). 
de 'originalidad' y 'copia'. La 'inventio' supone uno de los ideales cumbres de la tratadística del Renacimiento: el de la creación; mientras que el término 'imitatio'se reserva para una mímesis de la naturaleza o, en todo caso, del ideal de belleza clásico. Pero la 'imitatio' en el contexto de la pintura puede entenderse también como la dependencia formal de otra imagen, independientemente de sus fines. Sin embargo, Leonardo, por ejemplo, llega a tildar a la pintura de 'ciencia inimitable', que ni se copia como las letras (en las que tanto vale la copia como el original), ni se modela como en la escultura en la que el objeto modelado equivale al original; una disciplina incapaz de producir infinitos hijos iguales a ella (Da Vinci, 1965, Aforismo 126). Leonardo ofrece aquí algunas claves sobre aspectos de valoración de la copia, pero más allá de ello su afirmación constituye un reflejo de las tensiones y contradicciones referentes al asunto de las copias, situando a la pintura, como concepto ideal de inventio en la órbita de lo que no se puede imitar, por encima de otras artes y otras ciencias ${ }^{6}$. El mismo autor, sobre el concepto de imitatio, opina que nunca debe imitar un Pintor la manera de otro, porque entonces se llamará nieto de la naturaleza, y no hijo (Da Vinci, 1827, p. 11), y que si el pintor elige para modelos pinturas ajenas, las suyas serán de poca excelencia. Tales afirmaciones resultan paradójicas si se tienen en mente las frecuentes copias que salieron del taller del vinciano ${ }^{7}$, y la profusión con la que sus discípulos desarrollaron un estilo plenamente leonardesco. Y aún más, pudieran parecer contradictorias si se considera el hecho de que, pese a su rechazo a las copias $-\mathrm{y}$ a los procedimientos mecánicos para su consecución, que tanto entorpecían el juicio del ojo- en otros capítulos de su tratado recomiende el uso de parches transparentes para la obtención de calcos, velos, y otros ingenios que pudieron ser habituales en su taller ${ }^{8}$. Leonardo basta para constatar-como un mero paradigma más-, que las realidades teórica y práctica entran aquí, aparentemente, en colisión.

6 De hecho, estima la escultura como algo imitable y útil para aprender, pero considerado algo mecánico, y no intelectual.

7 Hoy sabemos que el ejercicio de la copia de sus dibujos y pinturas fue practicado por la mayoría de sus discípulos: de hecho, se conservan dibujos de Leonardo que mantienen vestigios de haber sido calcados o utilizados como modelos de transposición, como sucede en el caso del Retrato de Isabella d'Este, conservado en el Musée du Louvre, que presenta diminutos orificios en los contornos vestigios de su utilización como plantilla de estarcido. Otro ejemplo lo encontramos con 'Los Hernandos'. Hernando de Llanos y Fernando Yáñez de la Almedina trajeron, a su vuelta a Valencia hacia 1505, diversos modelos del taller de Leonardo, después de que, al menos, uno de los dos colaborase en las pinturas de la Gran Sala del Consejo de la Señoría, donde el maestro florentino se encontraba ocupado en el mural de La batalla de Anghiari (Benito, et al., 1998). Aun con ello, la práctica de la copia y la repetición, por ejemplo, está documentada también para la obra de Llanos (Herrero-Cortell y Puig, 2017, pp. 53-78). Por todo ello, y como sucede en la mayoría de textos de Leonardo, cabe establecer un posicionamiento crítico, que permita apreciar que la práctica de la copia fue más que habitual en su círculo.

8 "E se per lucidare una cosa tu non potessi avere un vetro piano, togli una carta di capretto sottilissima e e ben unta e poi secatta; e quando l'avrai adoperata per un disegno, potrai con la spugna cancellarla e fare il secondo'. (Da Vinci, 1817, p. 64). 
Lo cierto es que la imitatio en lo pictórico parece acarrear tradicionalmente connotaciones negativas, y la depreciación de las copias es ya una cuestión que se rastrea desde la literatura clásica y que perdura durante toda la Edad Moderna. Cuando Franciscus Junius (1638, pp. 348-349) en su tratado de 1638 se dirige a los Amantes del Arte da una serie de justificaciones de por qué las copias nunca llegan a igualarse a los originales, aduciendo que: "Those likewise that copy the most consummate pieces of excellent masters can seldome doe it so well, but that perpetually they fall away from the original". Con ese mismo pretexto cita comentarios de Dionisio de Halicarnaso, Cicerón, Plinio el Joven, Diógenes Laertes, o Quintiliano (1887, p. 42): "Nothing commendeth pictures so much as that authoritie given them by age which no art can imitate", aunque, a nuestro parecer llega a descontextualizar las sentencias de los clásicos para llevarlos a su terreno. A modo de colofón, puede resumirse el posicionamiento general de la alta literatura al respecto de las copias pictóricas en una la opinión de Felipe Guevara (1788, pp. 203-204) en sus Comentarios de 1560: "esto de la imitación es ahora, especialmente en nuestra España el principal estrago de los buenos ingenios de ella."

\section{USOS Y ABUSOS DE LAS GOPIAS PICTÓRICAS}

Para entender los diversos propósitos que fomentaron la realización de copias pictóricas, y los diferentes posicionamientos frente a sus usos -que motivaron tan dispares y ambiguas actitudes hacia al fenómeno-, no puede obviarse el contexto. A inicios de la Edad Moderna se desarrolló un flujo de copias creciente durante las siguientes dos centurias. La replicación de modelos pictóricos en Italia tiene su punto de partida en la tradición bizantina, hecho que se consolida con la repetición de imágenes devocionales, especialmente durante el siglo XVI (Moench, 2012, pp. 133-137). En Flandes, sin embargo, esta tradición se comenzó a dar a partir de los modelos de Rogier van der Weyden, y alcanzó ya un gran auge en la segunda mitad del siglo XV (Dijkstra, 1990), si bien esta tendencia aún crecería en centurias posteriores. En España, en cambio, no es hasta el siglo XVI cuando se asiste, por primera vez a un fenómeno de replicación de originales.

Básicamente hubo cuatro causas que motivaron la producción de copias pictóricas a inicios de la Edad Moderna: en primer lugar, las prácticas de taller que reaprovechaban los modelos en un equilibrio entre didáctica y mercado, contribuyendo así a consolidar el aprendizaje y a afianzar el estilo, y rentabilizando la producción de los maestros; en segundo lugar la imitación de modelos afortunados en el mercado artístico, tanto en el seno de los talleres como por parte de seguidores y epígonos, como respuesta a una demanda creciente; en tercer lugar, la repetición, replicación y reproducción de retratos áulicos, de monarcas, nobles, papas, o cardenales; por último el duplicado de las obras más afamadas y apreciadas, comisionadas por esa misma clientela. Aunque las cuatro causas presentan motivaciones bien distintas: las dos primeras responden más bien a una cuestión mercantilista y/o de 
optimización y rentabilización de tiempo y recursos; la tercera, en cambio, es fruto de una necesidad social de proyección, de omnipresencia icónica y simbólica $;$ y la cuarta, estrechamente relacionada con la tercera, responde al incipiente fenómeno del coleccionismo. Todas ellas conducen a la idea de la repetición, vinculándose al uso de los mencionados procedimientos mecánicos para la seriación y al incipiente apogeo de la estampa y su circulación ${ }^{10}$. Los oportunistas plagios y, en menor medida, las falsificaciones, no supusieron razones en sí mismas que motivasen la realización de copias, pero sí fueron fenómenos reales subyacentes a las mencionadas causas, y desde luego contribuyeron a denostar la valoración de las copias.

Pero, en términos generales, el prejuicio que emerge de las fuentes contra las copias pictóricas arranca en el cuestionamiento sobre el uso de técnicas mecánicas y semimecánicas para tal fin. Así aparece una cierta polarización: en un extremo el debate sobre la propiedad del uso de dichos procedimientos por parte de los artistas para reproducir sus propios patrones y en el otro el abuso que de tales métodos hacían artesanos poco capacitados, pintores sin inventiva, copistas que vivían de reproducir trabajos ajenos, y amateurs (Bambach, 1999, p. 127). No es de extrañar pues, que ya en el siglo XVI haya intentos de protección de los derechos intelectuales y que el acceso a la reproducción de algunas pinturas esté controlado, restringido o sencillamente vetado.

De un modo generalista existen dos grandes tendencias de opinión: una en la literatura culta (tratados y escritos de corte teórico) marcada por una constante censura a la copia; y la otra en la literatura técnica (libros de recetas, de reglas e instrucciones y otro tipo de escritos confeccionados por pintores o artesanos), textos en los que la actitud hacia las copias es mucho más laxa. Aún con ello, la finalidad resulta determinante en la posición que adopta el escritor, ya que ni siquiera existe un consenso de opiniones para cada uno de dichos bloques. A continuación, se abordan diversas motivaciones para el ejercicio de la copia pictórica, y se recogen posicionamientos diferenciados y matizados, que permiten comprender el choque entre teoría ideal y práctica real, y el porqué de tal colisión.

\subsection{Imitar para aprender: la copia de pinturas como ejercicio didáctico.}

Desde la antigüedad la copia directa a mano alzada era usada como un recurso de pedagogía del dibujo y la pintura, como sistema eficaz para desarrollar las

9 Nos referimos aquí a la imagen del poder, a una auténtica iconocracia que arranca, precisamente con el fin de la Edad Media, vinculada a la capacidad de ubicuidad de la efigie regia, tal y como queda abordado en Freedberg (1992).

10 Queda todavía pendiente de abordar el carácter análogo que llegarán a tener las abundantísimas pinturas sobre cobre en la diseminación de modelos: ejecutadas sobre soportes livianos y de pequeño formato, no solo contienen la esencia formal de la composición, sino que además dan noticia de los colores del original. Flandes, por ejemplo, fue un territorio pionero en la exportación comercial de este tipo de obras durante la Edad Moderna, pero también España encontró en este soporte una vía perfecta de exportación de imágenes al Nuevo Mundo. 
habilidades artísticas; un fenómeno que ya se rastrea documentalmente desde la Edad Media ${ }^{11}$. Su valor didáctico queda muy claro en el texto de Cennini (1998, p. 55) uno de los primeros en defenderlo, aunque con limitaciones:

“(...) habiéndote dedicado al dibujo, como te aconsejé más arriba, sobre tabla, dedicate ahora a copiar las mejores cosas que encuentres realizadas por los grandes maestros, mejor para ti. (...) Después dependerá de ti que, si la naturaleza te concedió algo de fantasía, llegues o no a desarrollar un estilo propio."

La primera limitación que expone Cennini es que nunca debe anteponerse la copia de otras obras a la imitación de la naturaleza, una idea constante en toda la tratadística posterior: parte del dibujo del natural acepta la copia como vehículo de aprendizaje en etapas más avanzadas de la formación del pintor. Además, en caso de copiar obras ajenas recomienda hacerlo de mano de los menos maestros que puedas, y a ser posible el mejor. Por último, condiciona la capacidad de desarrollar un estilo propio, al hecho de que el pintor tenga o no fantasía (inventio).

Aunque también Leon Battista Alberti, en De pittura (1435) recoge la idea del valor didáctico de la copia, rechaza todo aquello que no implique copiar del natural: así antepone la mimesis de la naturaleza a cualquier copia de producción artística humana y, relega las copias pictóricas a un último término, recomendando antes el dibujo de esculturas que la imitación de cualquier pintura, revelando su posición:

"Si acaso prefirieses copiar las obras de otros (...) me gustaría más que hubieras copiado una escultura mediocre que una pintura excelente. Nada más puede adquirirse de las pinturas que el saber cómo imitarlas; de la escultura puedes aprender a imitarla y a cómo reconocer y dibujar las luces" (Alberti, 2000, p. 128).

Leonardo, conocedor de los textos de Cennini y Alberti, aconseja únicamente copiar diseños como actividad formativa, posponiéndola en todos los casos al dibujo del natural. En estos términos lo expresa en la primera parte de su tratado: "El joven debe ante todo aprender la perspectiva para la justa medida de las cosas; después estudiar copiando buenos dibujos, para acostumbrarse á un contorno correcto" (Da Vinci, 1827, p. 3). Esta práctica contribuye a crear el conocido "giudizio dell'occhio"12, y por tanto sirve como entrenamiento para visualizar

11 Aunque aplicado al caso valenciano, de los siglos XIV y XV, destaca el trabajo de Montero (2015, pp. 322-338). Sobre la dualidad entre imitación y copia en la Edad Media véase el trabajo de Pérez (2012, pp. 85-121).

12 Este concepto se repite ya en Alberti y en Leonardo, y será clave en los círculos intelectuales artísticos del Renacimiento. Miguel Ángel también lo defendió a menudo, y otros autores como Anton Francesco Doni en su Disegno (1549), Vasari en su introducción a Le Vite (1550), Ludovico Dolce en su Dialogo (1557) o Raffaelle Borghini en Il Riposo (1584,) además de otros tantos de centurias posteriores. Sobre tal asunto especialmente interesante es el que texto de Bambach, The squaring Grid and the 'Giudizio dell'Occhio' (1999, pp. 128-133). 


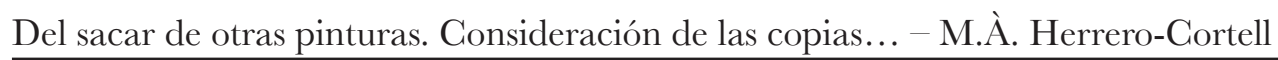

direccionalidades, angulaciones, o contornos. Nada menciona de la copia de pinturas, más allá de indicar la conveniencia de la observación de facturas de otros maestros "para adquirir facilidad en practicar lo que ya ha aprendido" $\mathrm{y}$, de hecho, en uno de sus aforismos (422), llega a explicar el por qué no defiende el ejercicio de la copia pictórica, aduciendo que genera malos hábitos. ${ }^{13}$

Giorgio Vasari, en su obra Le Vite (1550) aporta escasa información sobre la ejecución de copias pictóricas en su tiempo. De acuerdo con algunos autores, la omisión voluntaria de comentarios al respecto era un signo de desaprobación de este tipo de métodos (Galassi, 2013, p. 132); (Bambach, 1999, pp. 127-136). Sólo hay un pequeño fragmento en el que de manera ambigua puede entenderse un cierto alegato a la copia en el ejercicio del aprendizaje: "quien estudie las buenas pinturas y esculturas, bien realizadas, y además haga prácticas del natural, alcanzará, sin lugar a dudas, un buen estilo en el arte" (Vasari, 2002: 70-71). En cualquier caso su opinión al respecto de las copias es manifiestamente contraria, como se desprende de otros escritos de los que nos ocuparemos más adelante. Tampoco es el único que guarda silencio como signo de reprobación: Francisco de Holanda, por ejemplo, en el capítulo IX de La pintura Antigua (1549), cuando se refiere a cómo debe comenzar a aprender el pintor clarifica -ya en la primera línea-, que "no debe de contrahacer o imitar ningún otro maestro" (De Holanda, 2003, p. 46). Algo similar ocurre con Felipe Guevara en sus Comentarios de la Pintura (1560) en los que no dedica ninguna mención a la copia de pinturas, -en todo caso habla en términos de imitación, para referirse despectivamente- $\mathrm{y}$ descalifica cualquier copia que no sea del natural a excepción de determinadas obras de los antiguos, esgrimiendo, que: "gran ventura seria si los que estudian esta arte tuviesen juicio para entender en ella a quien habian de imitar" (Guevara, 1788, p. 203). Tampoco Ludovico Dolce, en su Dialogo della pittura (1557) menciona nada acerca de la copia pictórica con propósitos formativos. Únicamente alude a la utilización de modelos clásicos después de un aprendizaje del natural, como el resto de los mencionados, prefiriendo como Leonardo la copia de esculturas, y sometiéndola, de nuevo, al juicio del ojo:

"E per fare un corpo perfetto, oltre alla imitazione ordinaria della natura, essendo anco mestiero d'imitar gli antichi, è da sapere che questa imitazione vuole esser fatta

13 "A esto dice mi contrincante que, para hacerse práctica y producir obras en buen número, es mejor dedicar el primer periodo de estudio a copiar composiciones hechas sobre papel o en superficies murales por diversos maestros, y asi se practica velozmente y se adquieren buenos hábitos de trabajo. A lo que responderemos nosotros que esos hábitos serán buenos a condición de basarse en obras bien compuestas por maestros experimentados. Pero, siendo éstos tan raros que es difícil encontrarlos aún en corto número, es más seguro ir derechamente a los objetos que nos ofrece la naturaleza, antes que a las imitaciones que los empeoran y que nos inculcarian hábitos mezquinos. Porque no hay que beber de vaso cuando se puede ir a la fuente" (Da Vinci, 1965, Aforsimo 422).

Edición digital en: http://www.cervantesvirtual.com/obra-visor/aforismos-1/html/

[Consultado el 20-08-2015]. Esta misma idea, casi con idénticas palabras se recoge en Borghini (1584, pp. 139-140). 
con buon giudicio, di modo che, credendo noi imitar le parti buone, non imitiamo le cattive" (Dolce, 1735, p. 192).

También Borghini aboga por la copia de esculturas y relieves en el proceso de aprendizaje, supeditada al trabajo del natural: "percioche le cose che vengono dal naturale son quelle che fanno honore, e non dee qui disisdera divenir valenthuomo imitar la maniera d'alcuno, ma l'istessa natura da cui hanno gli altri apparato" (Borghini, 1584, p. 140). Resulta curioso que el autor se posicione en esta tesitura, especialmente si se tiene en cuenta que, en el mismo texto,-como se verá-, Borghini advierte hasta tres maneras diferentes de obtener soportes transparentes para calcar. La contradicción no lo es tanto si se considera que el escritor no es pintor, y pese a ser tratadista y crítico de arte, desconoce las verdaderas motivaciones de autores como Vasari al censurar los procedimientos mecánicos en las copias pictóricas. En cualquier caso, el texto de Borghini puede inscribirse en la tónica del discurso intelectual imperante.

Giovanni Battista Armenini es mucho más honesto en el equilibrio entre el plano ideal y el de la realidad pragmática, alejándose por primera vez de la tendencia generalizada de crítica hacia estos procedimientos. En De Veri Precetti della Pittura (1586), recomienda abiertamente el ejercicio de la copia como clave del aprendizaje y fuente de recursos:

"Y como estas pinturas se hallan dispersas por muchos pueblos y ciudades, es necesario ir a contemplarlas con tiempo y esfuerzo, y si es posible, tratar de copiarlas con colores sobre tablillas o papeles; todo o parte de sus cosas más bellas, y tener abundancia hechas al pastel u otra materia para servirse de ellas después según sea necesario" (Armenini, 2000, p. 91).

Por último cabría mencionar el absoluto y paradójico silencio que guardan Giovanni Paolo Lomazzo en su Trattato dell'arte della pittura, scoltura, et architettura $(1584)^{14} \mathrm{y}$, especialmente, Federico Zucaro, -acaso el pedagogo más influyente del final de Cinquecento, y presidente de la Accademia del Disegno en Roma, y Florencia- (Bambach, 1999, p. 127), en el segundo libro de su tratado L'Idea de 'pittori, scultori, et architetti, editado ya en 1607. Ni Lomazzo ni Zuccaro contemplan en ningún caso más imitación que la del natural y omiten voluntariamente cualquier referencia a las copias, prácticas que, por el contrario, caracterizaron la actividad pedagógica de todas las Academias.

Llama la atención, a tenor de lo expuesto en este epígrafe, tal parquedad de referencias a las copias pictóricas en el proceso de aprendizaje, o la omisión directa

14 Sin embargo, en su Idea del tempio della pittura de 1590, sí dedica unas líneas a quienes imitan el estilo de otros. El autor advierte que no solo copiar en sí es aprovecharse del esfuerzo ajeno, sino que, además, "imitare le maniere altrui \& abandonar la sua naturale è danosissimo al pittore" (Lomazzo, 1590, pp. 8-10). 
$\underline{\text { Del sacar de otras pinturas. Consideración de las copias... - M.À. Herrero-Cortell }}$

de esta práctica. Se conservan abundantes pruebas que avalan la formación de los artistas en los talleres de sus respectivos maestros haciendo uso de la práctica de la copia. De hecho, el propio Vasari relata en alguna ocasión cómo los pupilos de múltiples artistas copiaban obras de sus maestros para apre(he)nder la esencia de la pintura. La práctica fue seguida habitualmente en los talleres y ya desde el siglo XVI en las Academias, en las que se ha considerado, hasta nuestros días, una vía de probada utilidad en el aprendizaje (Prete, 1998, pp. 73-82); (Bimbi y Ragioneri, 2008).

2.2. El reciclaje mecánico de la 'inventio'. La copia pictórica como auxiliar en el taller: réplicas, versiones, series y procedimientos de calco.

Durante los siglos XV y XVI, los talleres pictóricos europeos desarrollaron mecanismos para convertirse en centros más expeditivos ante una demanda creciente de modelos afortunados ${ }^{15}$. Este fenómeno se da en paralelo en los territorios flamencos, italianos, hispanos, o franceses. Así, la reutilización de determinadas composiciones, o fragmentos de las mismas -figuras, motivos, patrones, arquitecturas etc.- se convirtió en un hecho común en la mayoría de los obradores.

Baste pensar para el caso italiano, en el anteriormente caso del taller de Leonardo, o los de Lorenzo di Credi, Perugino, los Lippi, Botticelli, o Domenico Ghirlandaio (Bambach, 1999, pp. 82-126); (Ganselli, 2012, pp. 82-117), el de Gentile da Fabriano (Caporaletti, 2014, pp. 67-75), o el paradigmático caso de Rafael (Pon, 2004), y su círculo (Cieri, 2012, pp. 63-74), por poner tan sólo algunos ejemplos. Mucho más exagerado es lo que acontece en Flandes, especialmente en talleres dedicados a pinturas devocionales, como el de Dirck Bouts, y más todavía en el de su hijo Albrecht en los que las series de algunas pinturas se cuentan por decenas (Hendericks, 2011). Pero incluso aquellas pinturas con temáticas diversas se ven sometidas al fenómeno de la clonación, tal y como sucede, por ejemplo, en el taller de Jan Massys, que sigue prototipos paternos (Galassi, 2012, pp. 12-19) también en el obrador de Pieter Brueghel el Joven, que llega a hacer docenas de copias de algunas obras de su padre (Francastel, 1995), o lo que acontece con los discípulos y seguidores de Holbein (Plender, 2012, pp. 12-19). En España, autores como Luis de Morales o Joan de Joanes recurren habitualmente a la repetición de composiciones y a la producción de versiones, continuadas por seguidores y epígonos, caso análogo al que sucede con El Greco (Marías 2016, pp. 85-110). En cierto modo se trató de algo propiciado por la 'Devotio Moderna' y la tipificación de la imagen, tanto en territorios flamencos - dedicados a la pintura devocional y a la estampa-, como en tierras hispanas, principales consumidores de aquellas obras (Martínez-Burgos, 1990, pp. 165-188), (Pereda, 2007, pp. 27-144).

15 Un estado de la cuestión fue aportado por Maison (1960). 
Por lo general en los talleres y obradores solían conservarse los bocetos, trazas, muestras, patrones y dibujos de las composiciones más afortunadas, y tanto el maestro como los discípulos y aprendices podían utilizarlos siempre que se precisaba (Bambach, 1999, p. 92). La copia de dibujos y pinturas y su sucesivo reciclaje, así como la labor cooperativa de diversos pupilos -entre ellos o con el maestro- se erigieron pronto como sistemas eficaces de trabajo. Frente a una elevada demanda en materia de pinturas destinadas a la devoción privada los maestros encuentran así una manera de aumentar la oferta y reducir el tiempo de trabajo (Gianeselli, 2012, p. 83). A tal efecto, existían una serie de métodos mecánicos y semimecánicos que facilitaban la labor. Papeles translúcidos, papeles de calco embebidos de carbón, cuadrículas, o plantillas de estarcir resultaban auxiliares imprescindibles en la mayoría de talleres, aligerando la tarea del dibujo a mano alzada y garantizando siempre su exactitud formal. Pero, de nuevo, las fuentes son muy parcas (Bambach, 1999, pp. 127-136): en buena parte de los textos se omite cualquier mención de tales procedimientos y tan sólo se encuentran esporádicas referencias en recetarios, libros de reglas de la pintura y textos de la 'baja literatura', escritos, en su mayoría por artesanos o artistas, y no por teóricos. Quizás, uno de los documentos más prolijos en lo alusivo a sistemas para calcar es el Manuscrito de Santiago de Compostela, titulado Reglas para pintar (Bruquetas, 1998, pp. 33-44).

Sin embargo, las menciones no son inexistentes. Cennini, por ejemplo, comenta la fabricación de papeles transparentes (Galassi, 2013, pp. 130-137), o 'carte lucide' indicando que resulta "muy útil para calcar una cabeza o una figura según la encuentres de la mano de grandes maestros" (Cennini, 1998, p. 52). Resulta curioso cómo Cennini nunca aclara la función de los calcos en el aprendizaje o en la dinámica de trabajo del taller, -más allá de su obvia finalidad de apropiación de un dibujo- ${ }^{16}$. Leonardo alude también a estas técnicas de calco (Da Vinci, 1827, p. 16), pero ni las defiende ni justifica abiertamente su uso, lo que no es de extrañar teniendo en cuenta la importancia que le otorga a la formación del criterio ocular. También Borghini (1584, pp. 144-146), menciona tres vías diferentes para obtener papeles transparentes para 'lucidare', así como el papel de carbón, pero como sucedía con Cennini nada aclara sobre su finalidad. Vasari (1963, p. 102), por su parte, desdeña, el uso de 'carte lucide', aduciendo que es una práctica de pintores sin habilidad para el dibujo, que sólo son capaces de calcar con papeles transparentes a partir de obras de otros maestros, y así decepcionar a la gente. Nada explica de otros métodos como la cuadrícula albertiana, aunque hay otra forma de calco transpositivo para tabla y lienzo que sí describe, aquel elaborado con cartones impregnados de carbón (Vasari, 2002, p. 72). Y a continuación exhorta que "el fin de dichos cartones es que la obra resulte justa y medida". Este comentario aclarara la intención con la que Vasari está justificando su mención, al tiempo que le sirve de manera sutil para reprobar un

16 Una disquisición sobre el silencio de Cennini a ese respecto la sostiene Nimmo y Olivetti (1985/86, p. 407). 
método que sabe que se utiliza con otros fines diferentes al que él recomienda. En definitiva, lo acepta únicamente como parte del proceso mecánico y creativo de un artista que permite materializar la 'inventio', con la finalidad de ahorrarle tiempo, y facilitar su trabajo. En esta misma dinámica aparece la mención a la 'graticola' o cuadrícula, en el Trattato dell'arte de Lomazzo (1584, pp. 276-277), justificando su uso como herramienta auxiliar para escalar dibujos propios, para ejercitarse en la perspectiva o "per ritrarre perche fa vedere più chiaramente la cosa dubiosa".

Vasari y Lomazzo dan en la clave del problema: el sistema es legítimo dependiendo de quién lo use. Para ambos el derecho de utilización de estos procedimientos queda relegado exclusivamente al entorno de un determinado artista, autorizado como creador para trabajar directamente en versiones de un mismo tema, o bien indirectamente mandándolas ejecutar o hacer. De hecho, el trabajo de estarcido, calco, o cuadrícula podía ser realizado por los mozos y aprendices, y no necesariamente por quien iba a pintar la obra. Con el tiempo los patrones, plantillas, cartones, y otros vestigios de estas labores pasaban a manos de discípulos, seguidores o epígonos más o menos vinculados al taller del maestro, y entonces se producía un segundo reciclaje de las imágenes, una apropiación deshonesta, al usar calcos ajenos que atajaban el trabajo y garantizaban la calidad de una composición que no era mérito de quien la ejecutaba. Baste, como colofón de lo anterior, recordar el carácter despectivo del apodo del pintor Niccoló Zoccolo, alias Cartoni, discípulo de Filippino Lippi, conocido así por su falta de talento, -tal y como recoge Vasari$(1568$, p. 497) tara que suplía mediante el uso de cartones o plantillas. El mote, casi un insulto-(Bambach, 1999, p. 31), es un claro reflejo de la consideración que los teóricos tenían por quienes desarrollaban una dependencia sistemática de estos procesos para suplir su falta de creatividad.

\subsection{Del original único al múltiple: copias pictóricas y divulgación de mod-} elos. Fortuna y desdicha.

La omnipresencia de las copias pictóricas se vio superada, o quizás reforzada, con la dispersión del grabado y las estampas. Este medio abre, precisamente, una nueva dimensión frente a la capacidad de ubicuidad de las copias: la de la divulgación de modelos, también con propósitos diversos: ejemplarizantes o didácticos, referenciales, modales, de concreción iconográfica, vinculados con el gusto, relacionados con la difusión de las imágenes del poder (Freedberg, 1992) o, una buena mayoría de las veces, devocionales (Martínez-Burgos, 1990, p. 167), evangelizadores (Pereda, 2007, p. 256), o incluso apotropaicos (Navarrete, 1998, p. $81)^{17}$.

17 Aunque aplicado para el caso de la Andalucía del siglo XVII, resulta muy conveniente el estudio de Navarrete (1998, pp. 23-86). 
Nada en claro se desprende de los textos de este periodo sobre las obras seriadas, las versiones y las réplicas de autor o taller, ni siquiera sobre el poder de la multiplicidad de imágenes, y son escasas las alusiones a las estampas, en creciente auge desde comienzos del siglo XVI. Hay que considerar que no es hasta finales del siglo XV, y sobre todo a partir del siglo XVI, cuando en Italia comienzan a proliferar las copias de pinturas, en paralelo a una exploración de las calidades artísticas del grabado y de sus cualidades de reproductibilidad (Zalamea, 2008, p. 63). Así, tampoco es de extrañar que la literatura artística tarde un tiempo en considerar este hecho, por lo que no es ya prácticamente hasta el siglo XVII cuando comienzan a atisbarse en la alta literatura posturas al respecto. Sin embargo, el poder de diseminación de las imágenes por la propagación del grabado fue mucho más rápido que cualquier respuesta al fenómeno: esta técnica llegó a transformar la noción del arte en Occidente, convirtiéndose a su vez en vehículo autorreferencial. Su poder reside en su capacidad de reproducción, difuminando y complicando los evanescentes límites entre la invención y la imitación. ${ }^{18}$

Y ciertamente el uso de estampas como modelos sirvió a los artistas en la realización de un corpus de soluciones compositivas y formales, recursos iconográficos en los que inspirarse, aun transgrediendo los límites del actual concepto de plagio. Los pintores privados de inventiva, pero con buenas dotes artísticas podían recurrir a soluciones ajenas de una manera digna. Así, en contraposición al sector más radical, constituido por Vasari o Zuccaro, Armenini $(2009$, p. 109) afirma que: "una vez adquirida la bella manera, uno puede servirse con facilidad de las cosas de otro, y con poco esfuerzo utilizarlas como propias, alcanzando honor sin ganarse el desprecio de nadie". Por tanto, un pintor no necesariamente había de tener 'inventio', si al menos tenía 'maniera', para gozar de una cierta consideración, siempre y cuando tuviese además criterio. Armenini, de hecho, mantiene una de las posturas más razonables con respecto a las copias, que recomienda más allá del aprendizaje, como se ha visto: él mismo asegura haberlas realizado, y normaliza la situación hasta el punto que menciona pintores que sólo trabajan con modelos ajenos, como Perino del Vaga, que utilizaba dibujos de Rafael, o estampas Durero, sin que por ello fuese considerado un mal pintor. Sin embargo, desvincula a estos pintores dotados de maniera pero carentes de inventio de los artífices faltos de ambas dotes, que contrahacían imágenes con otros propósitos, o bien que elaboraban pastiches a base de partes de otras pinturas, que resultaban obras faltas de unidad y harmonía. Sobre estos 'pintores' advierte:

"Para reconocer la diferencia entre este y el verdadero pintor, sabed que nada le es más familiar al primero que los patrones para estarcir, las estampas y las reglas, o lo que le distingue más que cualquier otra cosa es que, cuando llega al término de sus obras, no pide ser pagado por su ciencia e industria, pues en verdad no las hay, sino que lo que

18 Aunque no es el propósito de este artículo conviene no perder de vista la estrechísima relación entre grabados y copias pictóricas. Zalamea (2008), explora acertadamente esta vinculación. 
$\underline{\text { Del sacar de otras pinturas. Consideración de las copias... - M.À. Herrero-Cortell }}$

se mide es el precio de los colores que ha puesto, y el esfuerzo y el tiempo empleado" (Armenini, 2009, p. 62).

Menos concesiones hace Lomazzo (1590, p. 10) en su Idea del tempio della pittura, hacia quienes se valen del trabajo ajeno desarrollando su talento como copistas, considerándolos como "pittori di pessima conditione (...) di purgato spirito \& igengno più ottusso (...) gente di corta vista \& d'imperfetto giudizio", y exime a unos pocos nombres de imitadores de estilos ajenos, que sin embargo sí considera excelentes, como Daniello da Volterra o Sebastiano del Piombo que, más que copiar, siguieron el estilo de sus maestros.

Precisamente, la seriación incontrolada (la que escapaba al ejercicio de la réplica o versión, en los talleres de los respectivos autores), las más de las veces ejecutada por aficionados o pintores poco capacitados, contribuyó a denostar aún más el concepto de la copia pictórica (Bambach 1999, p. 136). A ese respecto es muy interesante la mención de Felipe Guevara (1788, p. 150) a las, tan abundantes como desafortunadas, reproducciones de retratos áulicos -a menudo elaboradas a partir de grabados- que proliferaron hacia el ecuador del siglo XVI, y que aún crecerían exponencialmente las dos siguientes centurias:

"Muchos pintores (como todos no sean muy excelentes en la imitación), por acreditar sus oficinas con semejantes retratos, suelen pintar, como á cada paso lo vemos, á algunos Príncipes tan fuera de término y de como son, que a mi juicio si los tales príncipes se viesen pintados quales por esas pandas y calles los traen, y por donde nunca fueron vistos habrían de dar buena razón la mitad de sus estados por no parecer tales quales estos pintores al mundo los muestran".

Fueron, precisamente, las bondades de la difusión de las imágenes las conllevaron también un mal uso de las mismas. La protección de los derechos de autor ante tal vorágine de copias sin control, llegó a ser un tema que preocupó a algunos pintores y artistas del Renacimiento, especialmente en Italia (Witcombe, 2004); (Korey, 2005, pp. 31-40). Sobre la protección intelectual de las imágenes, Tiziano, por ejemplo, obtuvo los privilegios venecianos que le permitían establecer un control sobre la impresión y publicación de grabados basados en algunas de sus pinturas (Ginsburg, 2012, p. 360), -aunque no parece estar claro si dichos privilegios protegían también las propias pinturas-(Pon, 1998, pp. 40, 47); (Korey, 2005, pp. 31-40), obras que a su vez eran replicadas masivamente por su propio taller (Cole, 1995, pp. 103105). Pero también se reportan casos hispanos: Damián Forment, escultor, tracista, y dibujante, reproducía algunas de sus creaciones en forma de estampas que mandaba grabar en de boj, reservándose sus derechos intelectuales al obligar al grabador a no poder ejecutar "otras plangas semejantes a las sobredichas" (Morte, 1995, p. 128).

Pero el celo por los derechos de las imágenes que gestó durante el siglo XVI, acabó redundando en la máxima protección de las mismas: en 1602, a imitación de las leyes romanas que prohibían la exportación de antigüedades de la Ciudad 
Eterna a cualquier otro punto del orbe, también la Academia en Florencia se ocupó de salvaguardar su patrimonio pictórico, evitando la diseminación de determinados ejemplares (Niglio 2016, pp. 1-13): así se creó una lista con obras que no podían exportarse bajo ningún concepto (Nobili, 1922, pp. 106), y que incluía nombres como Leonardo, Miguel Ángel Tiziano, Rafael, Perino del Vaga ${ }^{19}$, Filippino Lippi, Correggio, Il Parmigianino, inlcuso otros no tan conocidos hoy, como il Mecherino ${ }^{20}$. Este decreto, más allá del obvio cometido de salvaguarda de la más insigne producción de estos artífices, aseguraba un mecanismo de control sobre las copias que de dichas pinturas se ejecutaban.

Y es que, ante el fenómeno de la multiplicidad descontrolada, persistía el valor de la auténtica originalidad. Los mismos coleccionistas, que en ocasiones recurrían a copias, ${ }^{21}$ intentaban, a su vez, proteger sus propias obras de los copistas, precisamente para mantener su valor, y así se encuentran consejos como: "non prestare in alcun modo pitture per sverginarle con lassarle copiare", que le escribe Giulio Mancini ${ }^{22}$ a su hermano en 1608 (Maccherini, 1997, p. 80). Llama la atención lo contradictorio de esta sentencia frente al discurso de alegato, -casi de exaltación de las copiasque se colige en su obra Considerazioni sulla Pittura, escrita, hacia 1614. Entre los diversos consejos para los coleccionistas, dedica un capítulo al "Riconoscimento di pitture", en el que aborda la manera de discernir entre original y copia, desarrollando la idea de que la excelencia de determinadas reproducciones hace necesario distinguir entre éstas y sus respectivos modelos, y cómo algunas llegan a preferirse, incluso, más que un original, en tanto pueden ser más perfectas que aquel, y en esencia poseen dos artes: el arte de la invención (entendida como la repetición del patrón afortunado de un determinado) más la habilidad del copista, capacitado por tanto para mejorarlo (Mancini 1956-1957, pp. 134-135) ${ }^{23}$. Las advertencias de Mancini ponen de manifiesto la preocupación de los connaiseurs por la creciente proliferación de copias que desembocaba en un fenómeno de originalidad múltiple, las más de las veces fuera de control de los artistas ${ }^{24}$.

19 Llama la atención cómo un artista como Perin del Vaga, al que Armenini considera un buen pintor, quizás carente de inventiva, llega a ser tan apreciado como Leonardo, Michelangelo, Tiziano o Rafael, lo que viene a demostrar que la actitud de Armenini es consecuente con la realidad de su momento.

20 Domenico di Giacomo di Pace Beccafumi (1486-1551).

21 Para el caso de Tiziano véase el tecto de Cole (1995, pp. 104-105).

22 Este autor es uno de los iniciadores de método atribucionista, argumentando que en toda obra de arte está presente la identidad del personal del artista hasta en las más mínimas huellas de factura; dicha identidad se concentra en una característica manera de operar, en definitiva, en la idea de que la diferencia reside en los detalles.

23 Esto rompe con la idea de pintura 'inimitable' anteriormente expresada por Da Vinci.

24 Se ha considerado que los argumentos del Mancini formaban parte de una campaña de promoción para la colección de copias, asegurándose así, su propio éxito comercial, ya que el propio autor era marchante de arte y las copias formaban parte de su mercancía habitual. Sin embargo, esta aparente contradicción revela un problema de fondo: el del coleccionista especulador que precisa salvaguardar el valor del original evitando su devaluación, algo, que sin duda representa la otra cara de 
Sin embargo, volviendo a los siglos que nos ocupan, el problema de la originalidad múltiple no era visto como tal ni en Flandes ni en otros territorios septentrionales europeos, en los que la tradición de la copia tenía ya un consolidado arraigo desde inicios del siglo XV. Se ha sugerido un papel similar al de la literatura para el caso de las copias pictóricas flamencas: del mismo modo que Italia tenía una tratadística teórica afianzada que pautaba y normativizaba qué y cómo debía pintarse, la ausencia de este tipo de textos en Flandes por ejemplo, va ligada al uso que se hacía de las copias como medio de transmisión del conocimiento, hecho que explica cualquier falta de censura al respecto, y por tanto una concepción bastante diferente a la de los teóricos italianos (Martens, 2005, pp. 3-50).

Para concluir, no resulta entonces tan sorprendente que, a diferencia de lo que acontecía con los derechos de autor reivindicados por Tiziano, Durero no objetase nada al respecto de las copias de sus grabados, y sin embargo demandase exclusivamente la utilización indebida de su monograma, -en el que fuera acaso uno de los primeros pleitos por protección de autoría registrados- (Vasari, 1568, pp. 2-26); (Koerner, 2002, pp. 18-38); (Witcombe, 2004, pp. 81-85); (Andreoli, 2014, pp. 383-431). En lo sucesivo, el alemán llegaría a maldecir en escuetos epitafios en latín a los saqueadores e imitadores de la obra y el talento ajeno, tal y como se comprueba en las portadas de sus series de la Vida de la Virgen o la Pasión, ambas de 1511 (Jones, 1990, p. 120); (Andreoli, 2014, p. 383).

\section{4. ¿Lo original y lo único? Pinturas gemelas: autenticidad y falsificaciones en el Renacimiento}

El tradicional problema de atribucionismo referente a la identificación de originales y copias apareció muy tempranamente, reportándose casos, ya desde inicios del siglo XVI (Muller, 1989, p. 141). La búsqueda de los valores de la originalidad y la autenticidad se hacía necesaria en un mercado inundado de copias en el que los falsos fueron siempre de la mano de un creciente coleccionismo ${ }^{25}$.

Durante el Renacimiento se rastrean diversas anécdotas relacionadas con los fraudes pictóricos. Hans Holbein, por ejemplo, copiaba obras de maestros flamencos

\footnotetext{
la moneda de un complejo mercado existente conformado por hábiles copistas, potenciales compradores y un público que demanda al tiempo copias y originales (ZALAMEA, 2004, p. 64).

25 En términos generales, las falsificaciones durante el Renacimiento se centraron mayoritariamente en objetos de la Antigüedad Clásica: la insaciable demanda de los mismos llegaba a superar con mucho la demanda, hecho que propició que llegase a existir una industria consagrada a fabricar falsos antiguos, aunque éstos eran fácilmente detectables en los círculos de erudición propios de la Edad Moderna (Vico, 1555); (Tietze, 1948, p. 17). Ya en esa época era común imitar esculturas y objetos arqueológicos, tal y como recoge la mayoría de la literatura sobre el tema pero también pinturas, -aunque el volumen de las mismas recogido en la literatura resulta ínfimo si se compara con los falsos artísticos de otras disciplinas-. Muy interesante resulta el texto de NOBILI (1922, pp. 68-113) que construye una breve historia de las falsificaciones.
} 
y ocultaba el hecho (Martens, 2001, pp. 165-182); Condivi (1823, pp. 6-7) recoge, un pasaje que involucra a Miguel Ángel en una suerte de falsificación, al copiar una muestra de un retrato y entregar su copia a cambio, sin que su patrón lo percibiese; pero quizás la anécdota más conocida es la que relata Vasari $(2002$, p. 607) para la copia que Andrea del Sarto realizase de la obra de Rafael León X y sus sobrinos ${ }^{26}$. Según este autor, la copia era tan perfecta que engaña a Giulio Romano, uno de los colaboradores más cercanos del urbinés, que había intervenido en la ejecución de la original. Cuando Giulio es advertido de su verdadera naturaleza afirma que él no lo aprecia en menor medida que si fuese de Rafael por ser portentosa una imitación tan símil ${ }^{27}$.

Esta anécdota muestra una de las caras más amables del modo en el que se entendían las falsificaciones en la literatura renacentista: alabar las copias por su capacidad de engaño para dignificar la habilidad artística de un determinado autor fue algo habitual, llegando posteriormente a convertirse en un topos recurrente (Zalamea, 2008: 64), originado por opiniones como las de Vasari (1568, p. 383), a propósito de las falsificaciones escultóricas de Vellano:

"Tanto grande è la forza del contraffare con amore e studio alcuna cosa, che il piu delle volte, essendo benne imitata la maniera d'una di queste nostre Arti, da coloro, che nell'opere di qualcuno si compiacciono, si fattamente somiglia la cosa che imita quella che é imitata, che non si discerne se non da chi ha più che buon'occhio alcuna differenza."

De nuevo, el 'giuidicio' infalible del ojo hace presencia al final de la sentencia vasariana, evidenciado su supremacía -técnica y moral- frente a la impostura. Es precisamente en este juicio ocular en el que basa su peritaje Giulio Mancini. La cuestión de las falsificaciones y copias fraudulentas queda abordada en la primera parte de sus Considerazioni sulla Pittura, desarrollada en torno al arte de copiar, elogiando aquellas pinturas que no pueden distinguirse de sus respectivos originales:

"Con tutte queste osservanze distingüendo la copia dall'originale, nondimeno alle volte avviene che la copia sia tanto ben fatta che inganni, ancorchè l'artefice e chi compra sia intelligente, anzi, quello che è più, havendo la copia et l'originale, non sappia destinguere. Che in tal caso intesi il serenissimo granduca Cosimo di F.M. haver detto simil copie dover essere preferite all'originale per haver in sè due arti, e quella dell'inventore e quella del copiatore" (Mancini, 1956-1957, pp. 134-135).

26 Museo Capodimonte (Nápoles), 1525.

27 Esta anécdota, sobredimensionada probablemente por Vasari, pone de manifiesto un valor de las copias, acaso más cercano a nuestro tiempo, que de alguna manera también se inaugura en pleno Renacimiento: el de la reproducción como substituto del original. Sobre este tema: (Herrero-Cortell, 2016, pp. 11-21) 
$\underline{\text { Del sacar de otras pinturas. Consideración de las copias... - M.À. Herrero-Cortell }}$

Mancini advierte en su tratado que el comprador de falsificaciones celebra la imitación como habilidad artística, dignificando la copia y dotándola de una especial apreciación que podía hacerla, como ya se ha dicho, más deseable incluso que el original. Pero este tipo de copias ponían ya entonces, de manifiesto, el poder que tenía el artista sobre el experto (Müller, 1989, pp. 144-146); (Zalamea 2008, p. 64), reafirmando el valor de las copias como auténticas obras de arte, al tiempo que evidenciaba lo complejo del asunto. Sólo la pericia de las mejores manos era capaz de engañar a los connaisseurs, y la preocupación sobre la pretendida originalidad quedaba patente en muchos casos.

En una visita el 5 de enero de 1532 a la casa de M. Antonio Pasqualino, Marcantonio Michiel da noticia de una copia de una pintura de Giorgione que pasaba por ser presuntamente la original: "La testa del gargione che tiene in mano la frezza, fu de man de Zorzi da Castelfrancho, havuta da M. Zuan Ram della quale esso M. Zuane ne ha un ritratto, benche egli creda che sii el proprio" (Michiel, 1896, p. 78). Los coleccionistas ven peligrar el valor y la reputación de sus pinturas ante las temidas copias que se convierten, sin pretenderlo, en falsificaciones, y así se dan también los primeros casos de expertización, fundamentada en el confronto de pesquisas procedimentales y en la búsqueda de vestigios de unicidad, toques que no se pueden copiar (Müller, 1989, pp. 146-147), -acaso rasgos de aquella pretendida 'inimitabilidad' defendida por Leonardo-.

Para concluir baste citar el reporte que hace Felipe Guevara (1788, p. 42) sobre las falsificaciones de El Bosco, que proliferan en la España de su tiempo y que vienen a demostrar que, a pesar de las escasas referencias al tema halladas en la literatura, el asunto no entendía de fronteras y trascendía a la realidad artística del momento:

"Ansi vienen a ser infinitas las pinturas de este género, selladas con el nombre de Hyerónimo Bosco, falsamente inscripto, en las quales á él nunca le pasó por el pensamiento poner las manos, sino el humo y cortos ingenios, ahumándolas á las chimeneas para dalles autoridad y antigüedad."

Si bien las falsificaciones pictóricas no alcanzaron las cotas de sus homónimas en escultura o arqueología, su existencia contribuyó, a buen seguro, a denostar todavía más el ya de por sí empobrecido concepto de la imitación pictórica.

\section{GONGLUSIONES}

Durante el Renacimiento la nueva concepción de la pintura como praxis intelectual coincide con un fenómeno nuevo, cuyo auge era todavía inusitado: el de la multiplicidad. La copia pictórica se percibió como producto complejo y ambiguo, una tendencia orgánica que evolucionaba para adaptarse a las realidades artísticas de los territorios y sociedades del momento. Los textos de este periodo permiten hacernos una idea más clara de cómo la propia evolución de este fenómeno determinó 
la manera en la que entendieron los duplicados pictóricos, condicionados siempre por las circunstancias y factores concretos de cada lugar. Así, la copia se erigió como un fenómeno multicausal que respondió a exigencias diversas de los pintores, de los aprendices, de los comitentes y, en general, del mercado. Pero el asunto tuvo casi siempre una apariencia menos inocente de la que a priori pudiera parecer: más allá de las antedichas funciones, otros aspectos más turbios, -el del plagio y la falsificación- orbitaron habitualmente en torno al concepto, ensombreciendo esta práctica y contribuyendo a su denostación.

Como se ha explicado, la multiplicidad del original se atisbó como una ventaja y un problema a la vez. Por una parte, la tratadística italiana -y también la hispana tendió siempre a censurar la copia. Pero el ímpetu en exaltar la importancia de la inventio original redundó en una apreciación de aquellas invenciones más afortunadas; precisamente fue el propio éxito de las mismas lo que conllevaba, inevitablemente, su repetición. A ello contribuyó profundamente el uso de la estampa, pero también los procedimientos mecánicos y semimecánicos para la consecución de réplicas y versiones. El excesivo (ab)uso de estos procedimientos desató una censura contra quienes no sabían entender los nuevos derroteros ideológicos de la pintura, y se hacían dependientes de las formas y los lenguajes ajenos. Así la literatura desdeñaba las prácticas de quienes, renunciando a la invención, se conformaban con imitar; pero el mercado, sin embargo, parecía no hacerse eco de los dogmas de la teoría. De alguna manera, para los incipientes coleccionistas de arte, las copias constituían una vía de poseer una invención apreciada, aunque estuviese ejecutada por una mano diferente a la que la había concebido. El valor que un selecto público burgués, noble o eclesiástico otorgaba a la inventio, no iba por tanto aparejado a un valor análogo en la maniera, y así, ambas cualidades podían juzgarse independientemente, por más que buena parte de la tratadística pretendiese ligarlas de manera indivisible, y para este público la copia no era censurable.

Pero los textos también recogen posturas enfrentadas; por una parte existen escritos de corte teórico en los que se percibe una clara condena a cualquier vía de imitación; por otra, aquellos instructivos, dirigidos a quienes ejercitaban la práctica artística, que contienen claves para 'sacar' de otras pinturas haciendo uso de procedimientos de calco. En general, la literatura culta, que en realidad no era la que leían la inmensa mayoría de artistas y artesanos, arremetió contra los copistas, tildándolos siempre de pintores mediocres que se aprovechaban del trabajo ajeno, mostrando así cierta inquietud por una protección del trabajo intelectual. Eventualmente se llegó a valorar al copista por sus habilidades, especialmente cuando se trataba de grandes figuras que habían sido capaces de engañar a otros por la excelencia de su trabajo; cualidad que no debía ser, precisamente, la más frecuente.

Quizás el problema más importante que subyace en toda esta cuestión afecta directamente a las pretensiones y aspiraciones más hondas de la literatura y la teoría artística del momento: la razón por las que se sancionó la copia fue por considerarla 
una disciplina que adolecía una falta de 'inventio' como labor del intelecto. Ante la incipiente voluntad de diferenciarse de otras artes mecánicas había nacido la idea de la pintura inimitable, capaz de producir originales únicos e incorruptibles, una ingenuidad que jamás llegaría a trascender del plano ideal, vapuleada por una realidad bien distinta. La multiplicación descontrolada de las pinturas, el uso de procedimientos mecánicos y la falta de respeto, escrúpulos y calidad de muchos pintores, se convirtieron en lacras que hacían tambalear los postulados teóricos e ideológicos de los tratadistas. Pero especialmente las copias pictóricas suponían una contradicción insalvable al nuevo estatus pretendido: aquel en el que la pintura, desmarcada ya del resto de los oficios mecánicos se erigía en un arte liberal, intelectual y no manual, alejándose del peso de una tradición que relegaba al pintor a un mero artífice mecánico, un simple operario. Bajo esta premisa tales producciones seriadas, propias de artesanos, no tenían cabida.

Pero, contrariamente a la manifiesta voluntad de censura que emerge de la alta literatura, nada detuvo una praxis de la que, pese a que en ocasiones se hizo un mal uso, se reveló de gran utilidad en los múltiples propósitos de reproducción, derivados de una nueva manera de entender la pintura; con ella se atisbaba también una novedosa sensibilidad hacia los problemas de la originalidad, la autenticidad y la unicidad.

\section{REFERENCIAS}

Alberti, Leon Battista (2000). Tratado de la pintura. México: Universidad Autónoma Metropolitana.

Andreoli, Ilaria (2014). Heu tu Insidiator. Dürer et le faux. En: Natinel, Colette; Mouniel Pascale (dir.) Copier et contrefaire a la Renaissance. Faux et usage de faux. Paris: Honoré Champion, p. 383-431.

Bambach, Carmen (1999). Drawing and Painting in the Italian Renaissance Workshop. Theory and Practice, 1300-1600. Cambridge: Cambridge University Press.

Benhamou, Françoise; Ginsburgh, Victor (2006). Copies of artworks: the case of paintings and prints. Handbook of the Economics of Art and Culture, vol. 1, p. 253-283.

Benito, Fernando; Gómez, José; Samper, Vicente (eds.) (1998). Los Hernandos: Pintores hispanos del entorno de Leonardo. Valencia: Generalitat Valenciana.

Bimbi, Adriano; Ragionieri, Susanna (2008). Alla luce di un tempo: esercizi di copia, interpretazione e verzione dai maestri del Rinascimento. opere di Annalisa Betella, Mattia Colombo, Roberto Dragoni, Leonardo Magnani, Maddalena Tombaresi, Simone Zaccagnini. Roma: Polistampa.

Borghini, Raffaello (1584). Il Riposo. Florencia: Giorgio Marescotti.

Bruquetas, Rocío (1998) Reglas para pintar.Un manuscrito anónimo del siglo XVI. PH: boletín del Instituto Andaluz del Patrimonio Histórico, vol. 6, n. 24, p. 33-44. 
Caporaletti, Silvia (2014). A concorrenda o per fare esperimento quanto potesse avvicinarsi al suo maestro ecellente: la copia di Antonio da Fabriano da uno stendardo processionale da Gentile. En: Costa, Chiara (ed.) Tra vero e falso. Padova, p. 67-75.

Casini, Tommaso (2015). Falso, copia, riproduzione: lessico e critica. Annali di Critica d'Arte, n. 11, p.299-318.

Cieri, Claudia (2012). Polidoro da Caravaggio e Perin del Vaga a Roma: una competizione sull'antico fra invenzione, copia e variazione. Monumenta e Documenta, vol. 1, $\mathrm{n}$. 4, p. 63-74.

Cole, Bruce (1995). Titian and the Idea of Originality in the Renaissance. En: Ladis, Andrew y Wood. Carolyn (eds.), The Craft of Art: Originality and Industry in the Italian Renaissance and Baroque Workshop. Athens:University ofGeorgiaPress,p. 103-105.

Condivi, Ascanio (1823). Vita di Michelangelo Buonarroti. Pisa: Niccoló Capurro.

Da Vinci, Leonardo (1817). Trattato della pintura. Roma: Gugliemo Manzi.

Da Vinci Leonardo; Alberti; Leon Battista; Rejón de Silva, Diego (1827). El tratado de la pintura por Leonardo Da Vinci y los tres libros que sobre el mismo arte escribió Leon Bautista Alberti. Madrid: Imprenta Real.

Da Vinci, Leonardo (1965). Aforismos (Trad. García De Zúñiga, Eduardo.) Madrid: Espasa-Calpe, $3^{\mathrm{a}}$ edición. Edición digital en: http://www.cervantesvirtual.com/ obra-visor/aforismos-1/html/ [Consultado el 04/05/2017]

De Holanda; Francisco (2003). De la Pintura Antigua, Madrid: Visor Libros.

Dijkstra, Jeltje (1990). Origineel en kopie: een onderzoek naar de navolging van de Meester van Flémalle en Rogier van der Weyden. Tesis Doctoral. Amsterdam: University of Amsterdam.

Dolce, Ludovico (1735). Dialogo della Pittura. Florencia: Michele Nestenus et Francisco Moücke.

Francastel, Pierre (1995). Bruegel. Paris: Fernand Hazan, 1995.

Freedberg, David (1992). El poder de las imágenes. Madrid: Cátedra.

Galassi, Maria Clelia (2012). Copies of prototypes of Quentyn Massys from the workshop of his son Jan. En Hermens, Erma (ed.) European Paintings from 15th to 18th Centuries. London, p. 12-19.

Galassi, Maria Clelia (2013).Visual evidence for the use of 'carta lucida' in the Italian Renaissance workshop. En: Spring Marika y Meek (eds.), The Renaissance Workshop. Londres: Archetype Publications, p. 130-137.

García, Ángel (1992). La imitación poética en el Renacimiento. Kassel: Reichenberger y Publicaciones de la Universidad de Deusto.

Gianeselli, Matteo (2012). L'atelier du peintre: l'original multiple “. En: Moench, Esther (ed.) Primitifs Italiens: levrai, le faux la fortune critique, Milano: Silvana Editoriales, p. 83-117. 
$\underline{\text { Del sacar de otras pinturas. Consideración de las copias... - M.À. Herrero-Cortell }}$

Gianferrari, Melissa (2003). Nascita ed evoluzione di un supporto originale: la carta trasparente. OPD restauro, n. 15 , p. 245-254;

Ginsburg, Jane (2012). Proto-Property in Literary and Artistic Works: Sixteenth-Century Papal Printing Privileges. Colum. JL \& Arts, vol. 36, p. 345-458.

Guevara, Felipe (1788), Comentarios de la Pintura. Madrid: Gerónimo Ortega, Hijos de Ibarra y Cia.

Henderiks, Valentine (2011). Abrecht Bouts. Catalogue raisonnée, Buxelles: KIK-IRPA.

Herrero-Cortell, Miquel (2016). Arsgeminis pro ars. Las copias y reproducciones patrimoniales: usos, tendencias, percepción, y repercusión social. Revista de Museología, n.67, p.11-20

Herrero-Cortell, Miquel; Puig, Isidro (2017). Fernando de Llanos y la fortuna de la Virgo Lactans. Consideraciones técnicas y estilísticas para el estudio de un modelo de Virgen de la Leche en el Renacimiento valenciano. Archivo de Arte Valenciano, $\mathrm{n}$. 98, p. 53-78.

Jones, Mark (1990). Fake?: The Art of Deception . Berkeley: University of California Press.

Junius, Franciscus (1638). The painting of the ancients, in three bookes : declaring by historicall observations and examples, the beginning, progresse, and consummation of that most noble art, and how those ancient artificers attained to their still so much admired excellenci., London: Hodkinsonne.

Koerner, Joseph (2002). Albrecht Dürer: A Sixteenth-Century Influenza. En: Bartrum, Giulia et al. (eds.), Albrecht Dürer and his Legacy. The Graphic Work of a Renaissance Artist. Princeton: Princeton University Press p. 18-38.

Korey, Alexandra (2005). Creativity, authenticity, and the copy in early print culture. En: Zorach, Rebecca (ed.), Paper Museums: The Reproductive Print in Europe, 15001800. Chicago: Smart Museum of Art, The University of Chicago, p. 31-40.

Lomazzo, Giovanni Paolo (1584). Trattato dell'arte della pittvra, scoltvra, et architettvra. Milan: Paolo Gottardo.

Lomazzo, Giovanni Paolo (1590). Idea del tempio della pittura, Milan: Paolo Gottardo.

Maccherini, Michele (1997). Caravaggio nel carteggio familiare di Giulio Mancini. Prospettiva, n.86, p. 71-92.

Maison, K. E. (1960). Themes and Variations, Five Centuries of Master Copies, and Interpretations. London: Thames and Hudson.

Mancini, Giulio (1956-1957). Considerazioni della Pittura. Roma: Accademia Nazionale dei Lincei.

Marías, Fernando (2016). El Greco, viejos y nuevos problemas: El Greco y Jorge Manuel Theotocópuli. En: Albl, Stephan y Aggujaro, Alina (eds.), Il metodo del conoscitore: Approcci, limiti, prospettive. Roma: Artemide, p. 85-110. 
Martens, Didier (2001). Die Würde des Kopisten oder Hans Holbein. Die Auseinandersetzung mit einem flämishen Vorbild. Städel Jahrbuch n. 18, p. 165-182.

Martens, Didier (2005). De saint Luc peignant la Vierge à la copie des Maîtres : la 'norme en acte' dans la peinture flamande des XVe et XVIe siècles. Revue belge d'Archéologie et d'Histoire de l'Art, n. LXXIV, p. 3-50.

Martínez-Burgos, Palma (1990). Ídolos e Imágenes. La controversia del arte religioso en el siglo XVI español. Valladolid: Secretariado de Publicaciones de la Universidad de Valladolid/ Caja Salamanca.

Melli, Lorenza (2001). Sull'uso della carta lucida nel Quattrocento e un esempio per il Pollaiolo. Parangone vol. LII, n. 36, p. 3-9.

Michiel, Marcantonio (1896). Der Anonimo Morelliano: Marcantonio Michiel's notizie d'opere del disegno, Vienna: Theodor Frimmel.

Moench, Esther (ed.) (2012). L'oeuvre et son doublé: le modèle répété. En: Primitifs Italiens: levrai, le faux la fortune critique Milano: Silvana Editoriales, p 133-163.

Montero, Encarna (2015). La transmisión del conocimiento en los oficios artísticos: Valencia, 1370-1450. Valencia: Institució Alfons el Magnànim.

Morte, Carmen. (1995). Damián Forment, escultor de la Corona de Aragón. En: Fernandez Pardo, Francisco (cord.) Damián Forment, escultor renacentista. Santo Domingo de la Calzada: Catedral de Santo Domingo de la Calzada, p. 115-176

Müller, Jeffrey (1989). Measures of Authenticity: The Detection of Copies in the Early Literature on Connoisseurship. Studies in the History of Art. Symposium Papers VII: Retaining The Original: Multiple Originals, Copies, and Reproductions. London: National Gallery of Art, vol. 20, p. 141-149.

Navarrete, Benito (1998). La pintura andaluza del siglo XVII y sus fuentes grabadas. Madrid: Fundación de Apoyo a la Historia del Arte Hispánico.

Niglio, Olimpia (2016). La política cultural en Italia y las innovaciones del siglo XXI. Culturas. Revista de Gestión Cultural, vol. 3, n, 1, p. 1-13.

Nimmo, Mara; Olivetti Carla (1985-1986). Sulle tecniche di trasposizione dell'immagine in época medioevale. Rivista dell'Istituto Nazionale d'Archeologia e Storia dell'Arte, n.VIII-IX, p. 399-411.

Nobili, Riccardo (1922). The Gentle of Faking. London: Seeley Service and Co.

Pereda, Felipe (2007). Las imágenes de la discordia: política y poética de la imagen sagrada en la España del cuatrocientos. Madrid: Marcial Pons.

Pérez, Olga (2012). Producción artística en la Baja Edad Media: originalidad y/o copia”. Anales de la Historia del Arte, n. 22, p. 85-121.

Plender, Sophie (2012). Copies and versions: discussing Holbein's legacy in England; Technical examination of copies of Holbein portraits at the National portrait Gallery. En Hermens, Erma (ed.), European Paintings from 15th to 18th Centuries. London: National Gallery Publications, p. 12-19. 
$\underline{\text { Del sacar de otras pinturas. Consideración de las copias... - M.À. Herrero-Cortell }}$

Pon, Lisa (1998). Prints and Privileges. Regulating the Image in Sixteenth-Century Italy. Harvard University Art Museums Bulletin vol. 6, n. 2, p. 40-64 .

Pon, Lisa (2004). Raphael, Dürer and Marcantonio Raimondi. Copying and the Italian Renaissance Print. New Haven: Yale University Press.

Prete, Cecilia (1998). L'insegnamento della copia nell'Accademia di Belle Arti di Firenze e i copisti nella Reali Gallerie, En: Piero Interpretato, Ancona, p. 73-82.

Quintiliano (1887). Instituciones Oratorias, Libro VIII, Capítulo III, Tomo II, Madrid: Imprenta de la Viuda de Hernando.

Tietze, Hans (1948). Genuine and false: Copies, imitations, forgeries. London: Max Parrish.

Vasari, Giorgio (1568). Le vite de' più eccellenti architetti, pittori, et scultori italiani, da Cimabue insino a' tempi nostri. Florencia, Tomo V.

Vasari, Giorgio (1963). 'Lettera a Benedetto Varchi' [1547]. En: Barocchi, Paola (ed.) Trattati d'arte del Cinquecento, tra manierismo e Controriforma. Bari: Laterza, vol. I.

Vasari, Giorgio (2002). Las vidas de los más excelentes arquitectos, pintores y escultores italianos desde Cimabue hasta nuestros días. Madrid: Cátedra.

Witcombe, Christopher (2004). Copyright in the Renaissance. Prints and the 'Privilegio' in Sixteenth-Century Venice and Rome. Boston: Brill.

Zalamea, Patricia (2008). Del Grabado como estrategia: mediación entre originales y copias. Revista de Estudios Sociales, n.30, p. 58-71.

Zucaro, Federico (1768). L'Idea de 'pittori, scultori, et architetti. Roma: Marco Pagliarini. 